\title{
Argon plasma coagulation of a bleeding angioectasia in a jejunal diverticulum by single-balloon enteroscopy
}

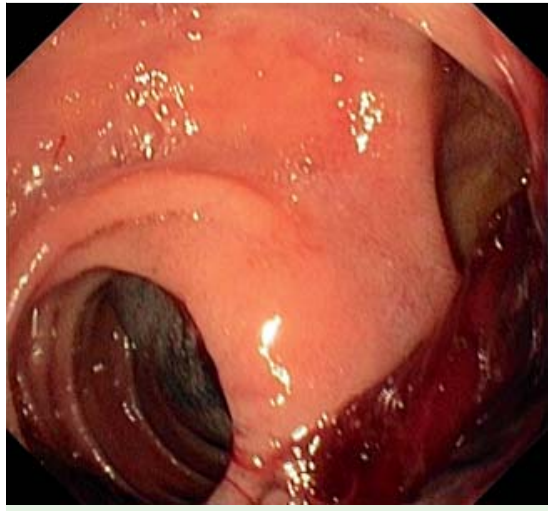

Fig. 1 A large diverticulum in the proximal jejunum with a bulky clot.

An 86-year-old woman with a history of cardiac and chronic renal failure was referred to our gastroenterology outpatient clinic because of an iron deficiency anemia and intermittent, self-limited hematochezia episodes. Colonoscopy and upper endoscopy revealed no alterations. A capsule endoscopy showed a nonbleeding angioectasia in the proximal ileum. Single-balloon enteroscopy was proposed to treat the angioectasia. During the procedure, a large jejunal diverticulum with a bulky clot was seen in the proximal jejunum ( Fig. 1). The clot was removed after water irrigation, and an oozing bleeding was found from an angioectasia located in the fundus of the diverticulum ( $\bullet$ Fig. 2). Distal tattooing was performed. Bleeding was then controlled with combination therapy: first a submucosal epi-

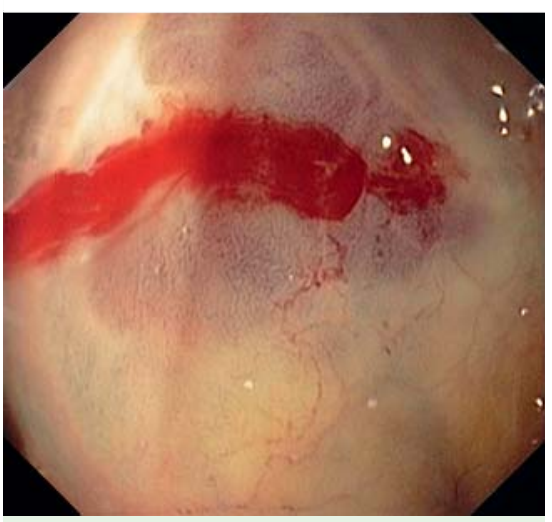

Fig.3 Appearance after submucosal epinephrine injection to control bleeding.

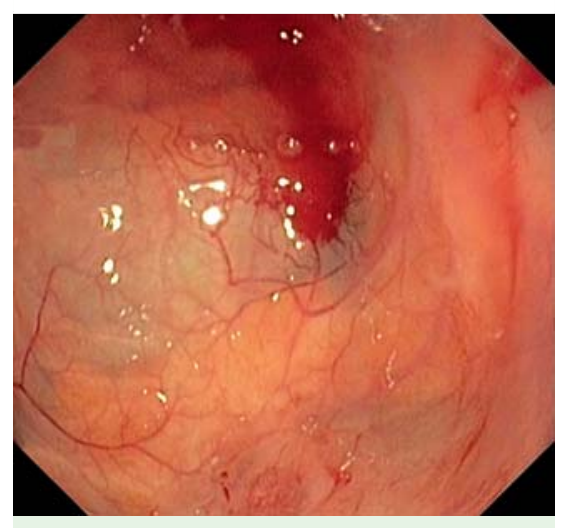

Fig. 2 Bleeding angioectasia located in the fundus of the diverticulum.

nephrine injection ( $\bullet$ Fig.3) followed by argon plasma coagulation (APC) of the angioectasia ( $\bullet$ Fig.4). No immediate or delayed complications were recorded, and there was no recurrence of bleeding during 1 year of follow-up.

Small-bowel diverticula are a rare condition usually characterized by mucosal and submucosal herniation through the muscular layer on the mesenteric border [1]. Although they are usually asymptomatic, malabsorption, abdominal discomfort, obstruction, bloating, bleeding, or perforation may occur [2]. Currently, capsule enteroscopy and device-assisted enteroscopy are the mainstays for diagnosis [3]. Small-bowel angioectasias are a common cause of obscure gastrointestinal bleeding, mostly in the elderly. APC by device-assisted enteroscopy has been shown

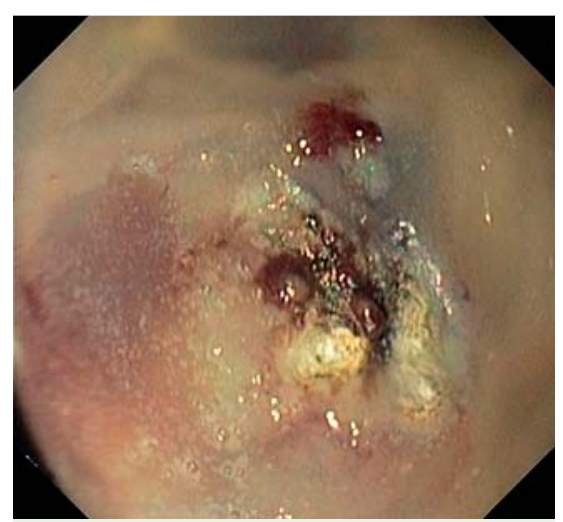

Fig.4 Appearance after argon plasma coagulation of the angioectasia. to be effective and safe in the management of small-bowel angioectasias [4]. Identification of a bleeding angioectasia in a jejunal diverticulum is an exceptional finding. The risk of diverticular perforation after APC may be increased. To the best of our knowledge, this is the first case report of APC by single-balloon enteroscopy in a bleeding angioectasia located in a jejunal diverticulum.

Endoscopy_UCTN_Code_CCL_1AC_2AF

Competing interests: None

Carlos Fernandes ${ }^{1}$, Rolando Pinho ${ }^{1}$, Adélia Rodrigues ${ }^{1}$, Germano VilasBoas ${ }^{2}$, Iolanda Ribeiro ${ }^{1}$, Joana Silva ${ }^{1}$, Ana Ponte ${ }^{1}$, João Carvalho ${ }^{1}$

${ }^{1}$ Department of Gastroenterology and Hepatology, Centro Hospitalar Vila Nova Gaia/Espinho, Vila Nova de Gaia, Portugal

2 Department of Gastroenterology, Hospital Pedro Hispano, Matosinhos, Portugal

\section{References}

1 Williams RA, Davidson DD, Serota AI et al. Surgical problems of diverticula of the small intestine. Surg Gynecol Obstet 1981; 152: 621-626

2 Johnson KN, Fankhauser GT, Chapital AB et al. Emergency management of complicated jejunal diverticulosis. Am Surg 2014; 80: 600-603

3 Ell C, May A, Nachbar L et al. Push-and-pull enteroscopy in the small bowel using the double-balloon technique: results of a prospective European multicenter study. Endoscopy 2005; 37: 613-616

4 Samaha E, Rahmi G, Landi B et al. Long-term outcome of patients treated with double balloon enteroscopy for small bowel vascular lesions. Am J Gastroenterol 2012; 107: $240-246$

\section{Bibliography}

DOI http://dx.doi.org/

10.1055/s-0034-1390918

Endoscopy 2015; 47: E62

(c) Georg Thieme Verlag KG

Stuttgart · New York

ISSN 0013-726X

\section{Corresponding author}

\section{Carlos Fernandes}

Centro Hospitalar Vila Nova Gaia

Gastroenterology and Hepatology

Rua Conceição Fernandes

Vila Nova de Gaia 4434

Portugal

Fax: +351-22-7830209

carlosdpfernandes@gmail.com 